\title{
IR measurements of hypersonic viscous interaction
}

\author{
by CARDONE G.*, DE LUCA L." ASTARITA T.* \\ AYMER DE LA CHEVALERIE D. ${ }^{\circ}$ and FONTENEAU A.
}

* University of Naples, DETEC, P.le Tecchio, 8080125 Naples, Italy

- LEA URA 191, CEAT rue de l'aerodrome 43, Poitiers F-86036, France

\begin{abstract}
Heat transfer measurements performed by means of an Infrared Scanning Radiometer in a blowdown hypersonic wind tunnel are discussed. In particular, the formation of Goertler-type vortices in the reattaching flow region over the flap following a flat plate is investigated, as well as its influence on the wall heat transfer distribution. Tests are carried out within the European Community Hermes space program to develop the first european space shuttle.
\end{abstract}

\section{Introduction}

The need to solve the problems concerned with high-speed flight, related, for example, to the design of modern re-entry shuttles, recently produced a renewed interest about the aerothermodynamics of space vehicles. Parallel to the development of more sophisticated numerical codes, an accurate and comprehensive wind tunnel testing, including a more detailed measurement of thermal loads, is required.

Both qualitative and quantitative measurement methods are necessary. The former (e.g. surface flow visualization by oil films or temperature sensitive coatings) yield generally an overall view of the most critical regions, the latter (thermocouples, wall calorimeters, thin films) provide accurate information to validate numerical codes. Standard quantitative techniques typically give a zero-dimensional measurements, i.e. each measurement is taken at a single point over the model surface. Surface flow visualization techniques can yield a twodimensional surface mapping of the flow field, but they may affect the flow boundary conditions near the solid wall.

In the last decade the good results attained by means of a widespread use of the Infrared Scanning Radiometer (IRSR) in convective heat transfer problems have proved IRSR to be one of the best tools to overcome several limitations of standard heat flux sensors, both from the measurement and the visualization points of view.

As mentioned in Ref. [1] the set-up of computerized quantitative IR thermography needs the solution of several problems mainly concerned with: an accurate characterization of the IR imaging system performance; the calibration of the IR camera; the use of external additional optics and/or mirrors, e.g. to increase the spatial resolution; the determination of the critical identification of the measured points; the design of the optical access window including the choice of the most appropriate IR materials.

The essential features of an IR imaging system are: it is truly non-intrusive; it allows for a fully two-dimensional mapping of the surface to be tested; the video signal output may be treated by digital image processing $[2,3]$. Accordingly, it can be successfully applied to both thin-skin and thin-film techniques [4-10].

In this paper significant results referring to heat transfer measurements performed with an IRSR in a blowdown hypersonic wind tunnel to study some cases of $2 D$ shock/boundary layer interaction are discussed. Present tests are carried out within the European Community Hermes space program to develop the first european space shuttle. 


\section{Experimental rig}

Experimental tests have been carried out in the hypersonic blowdown tunnel $\mathrm{H} 210$ of CEAT, Poitiers (having a test section diameter of $210 \mathrm{~mm}$ ). The operating fluid is dry air which has typically a stagnation temperature $T_{0}=780 \mathrm{~K}$ and a stagnation pressure $3 \mathrm{MPa}<p_{0}<$ $9 M P a$. Unit free stream Reynolds number $R e_{m}$ is changed mainly by varying the stagnation pressure and, in present tests, ranges from $7.6 \times 10^{6} / \mathrm{m}$ to $24 \times 10^{6} / \mathrm{m}$. A properly designed nozzle has been employed to obtain a nominal free stream Mach number equal to 7.14. In effect, Mach number slightly depends on the stagnation pressure due to the interaction of the nozzle boundary layer thickness.

At the beginning of each test run the model (which is initially in a remote position at room temperature) is vertically injected into the stream. The time rise of its surface temperature is measured by viewing the model with an infrared (IR) camera. A time sequence of thermograms (average time step is $1 / 15 \mathrm{~s}$ ) is generally recorded during the test runs. Injection time is about $0.15 \mathrm{~s}$ and testing duration of a few seconds.

The lay-out of the model employed to obtain the data here after presented is reported in Fig.1. As far as the model material is concerned, the ramp is made of solid RTV 147, while the flat plate is made of solid plexiglas. The physical properties of the plexiglas and RTV 147 are: $\rho=1190 \mathrm{Kg} / \mathrm{m}^{3}, k=0.19 \mathrm{~W} / \mathrm{mK}, c=1470 \mathrm{~J} / \mathrm{kgK}$ and $\rho=1280 \mathrm{Kg} / \mathrm{m}^{3}, k=0.31 \mathrm{~W} / \mathrm{mK}, c=$ $1047 \mathrm{~J} / \mathrm{kgK}$, respectively, where $\rho$ is the density, $k$ the thermal conductivity and $c$ the specific heat coefficient. Data will be discussed for flap angle values of $10^{\circ}, 15^{\circ}$ and $20^{\circ}$ and sharp leading edge.

The use of RTV is motivated by the consideration that, owing to its relatively low thermal diffusivity coefficient $\left(\alpha=2.34 \times 10^{-7} \mathrm{~m}^{2} / \mathrm{s}\right)$ the thermal sensivity in detecting spanwise temperature fluctuations is enhanced. Moreover, the thermal penetration depth is very small and the thin film sensor model (semi-infinite wall) can be used to correlate wall temperature to heat transfer coefficient.
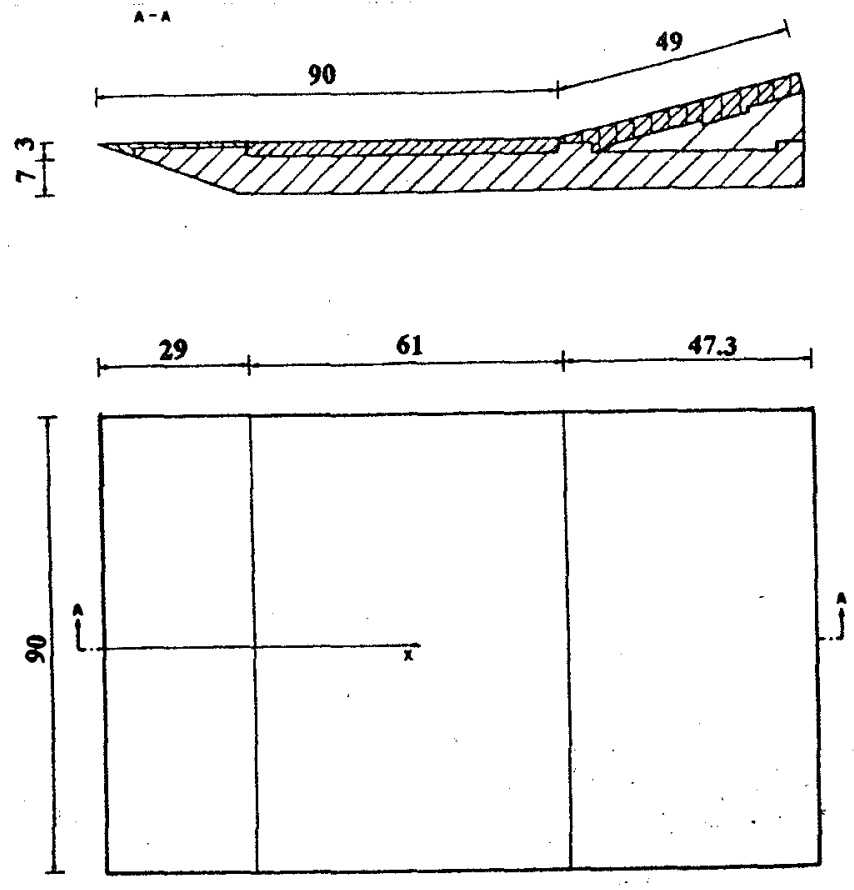

Fig.1 - Model lay-out 
http://dx.doi.org/10.21611/qirt.1994.023

Where the measurement surface is made of plexiglas, in order to enhance IR radiation detection it has been necessary to coat it with a (thermally) black paint. On the contrary, RTV surface emissivity coefficient is sufficiently high (the measured value in the IR wavelength range of measurement is about .93), so that IR measurement can be carried out without any painting.

The AGEMA 900 IR System has been employed to obtain the data here after presented. The total field of view, which depends on the employed optics is scanned by the $\mathrm{Cd}-\mathrm{Te}-\mathrm{Hg}$ detector (working in the 8 to $12 \mu \mathrm{m}$ IR window) and a frame of 136 not-interlaced lines is produced in $1 / 15 \mathrm{~s}$. Nominal sensitivity, expressed in terms of noise equivalent temperature difference, is $0.07{ }^{\circ} \mathrm{C}$ when the scanned object is at ambient temperature. The scanner spatial resolution indicated by AGEMA is 230 instantaneous fields of view (IFOV's) per line at $50 \%$ slit response function (SRF). A/D conversion (12 bits) is performed within the camera itself. The computerized system allows one to acquire a time sequence of thermal images.

The system software for the acquisition and handling of the thermal image (which consists of a frame of $272 \times 136$ pixels) is the so called AGEMA ERIKA. Data may be acquired in both real time and frozen modes. All the other details basically concerned with the viewing procedure may be found in [10].

Fig. 2 depicts the two optical configurations employed during the present tests. The first one refers to the basic configuration for which a frame of $180 \times 90 \mathrm{~mm}^{2}(1.5$ pixels $/ \mathrm{mm})$ is obtained at a viewing distance of $1 \mathrm{~m}$. The latter has been designed in order to obtain a higher spatial resolution. In this case a spherical mirror $(120 \mathrm{~mm}$ in diameter and having a focal length of $600 \mathrm{~mm}$ ) has been employed so as to obtain a frame of $60 \times 30 \mathrm{~mm}^{2}$ (i. e. a spatial resolution of 4.5 pixels $/ \mathrm{mm}$ ).
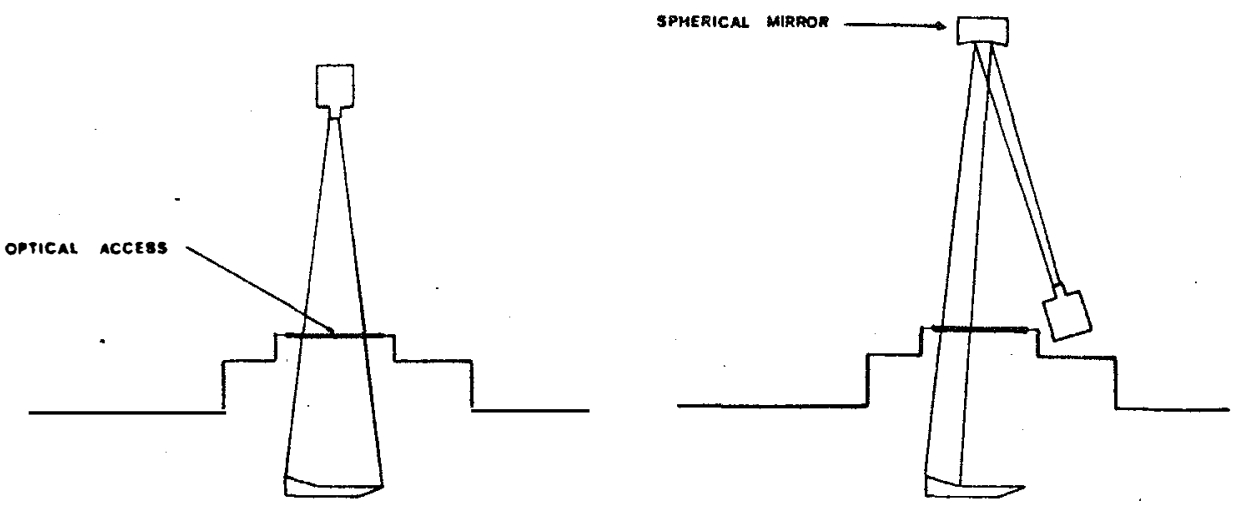

Fig.2 - Optical configuration

\section{Data reduction}

As already mentioned, because of the short measuring time, the thermal penetration depth can be generally considered

one-dimensional semi-infinite wall thermal model can be applied. The present application constitutes an inverse heat conduction problem since the estimation of the surface heat flux is required, given (at every pixel location) the measured temperature history inside the (heat conducting) body.

It is well known that if the temperature time history of a solid (with constant thermal properties) is known (e.g., a measured wall temperature) a relatively simple exact solution 
exists for the heat flux. The known surface temperature specification yields a simpler inverse problem because the wall temperature can be treated as a boundary condition in the traditional sense. Moreover, if only the heat flux is of interest, it is not necessary to calculate the entire temperature field as the heat flux at the boundary can be determined from the Fourier's law. Being the analysis restricted to the one-dimensional semi-infinite solid, the net exchanged heat flux $q(t)$ at the instant $t$ can be expressed as:

$$
q(t)=\sqrt{\frac{\rho c k}{\pi}}\left[\frac{\phi(t)}{\sqrt{t}}+\int_{0}^{t \phi(t)-\phi(\lambda)} \frac{(t-\lambda)^{3 / 2}}{(t \lambda}\right]
$$

where $q(t)=q_{c}(t)-q_{r}(t)$ represents the difference between the convective heat flux and the radiative one. $\phi$ is the temperature difference $T_{w}(t)-T_{w i}, T_{w i}$ being the initial value of the wall temperature. The integral of eq. (1) may be evaluated numerically by using one of the algorithms generally accepted for aerospace application (e.g. [11]). However, generally such algorithms are sensitive to temperature measurement errors and one should be very cautious when using them with noisy data.

An altemative approach that the experience showed to work better [12] is based on the assumption that the direct problem suggests a certain time variation law for the heat flux, introducing a number of free parameters. Such parameters can be then found so that the computed temperatures agrees (to a certain accuracy level) with the experimentally measured temperatures. The extent of the agreement or fit is determined by the ordinary least squares criterion.

In the case of flow conditions invariant during a test, the heat transfer rate is going to vary linearly with the wall temperature for a constant heat transfer coefficient $h$ :

$$
q_{c}=h\left(T_{a w}-T_{w}\right)
$$

The solution of the heat diffusion equation in solids based on the above boundary condition may be obtained by Laplace transform as:

$$
\frac{T_{w}-T_{w i}}{T_{a w}-T_{w i}}=1-e^{\beta^{2}} \operatorname{erfc}(\beta)
$$

with $\beta=\frac{h \sqrt{t}}{\sqrt{\rho c k}}$ and $\operatorname{erfc}(\beta)=1-\operatorname{erf}(\beta)$. So in the present case the least squares method consists of finding $h$ and $T_{a w}$ in order to minimize the function:

$$
S=\sum_{j=1}^{n}\left(Y_{j}-T_{w j}\right)^{2}
$$

where $Y_{j}$ is the j-term of the $n$ experimentally measured temperature values and $T_{w j}$ is the predicted one, both of these being taken at time $t_{j}$ and at the same location.

Further details concemed with the system software and data numerical treatment may be found in Ref. [10]. It has just to be pointed out that in the present tests, because of the higher camera spatial resolution as well as relatively lower heat transfer fluctuations wavelength, the need of applying an image restoration on the acquired data is practically negligible.

The streamwise Stanton number distributions over the studied flat plate/ramp configuration are reported in Fig. 3 for a flap angle of $10^{\circ}$ and three different Reynolds numbers. For the model under consideration the hinge line is located at $x=90 \mathrm{~mm}$. The practically sudden decrease of the heat transfer coefficient recovers the laminar nature of the viscous interaction. The St variations for flap angles of $10^{\circ}, 15^{\circ}, 20^{\circ}$ and $R e_{m}=8.6 \times 10^{6}$ are shown in Fig. 4. The effect linked to the increase of the flap angle is that of moving upstream the location of the laminar separation. The Stanton number value over the ramp appears higher at the highest 
http://dx.doi.org/10.21611/qirt.1994.023

ramp angle of $20^{\circ}$ (due to the stronger interaction) for which it attains the maximum value at the lowest Reynolds number.

Note that the reported St distributions over the ramp refer to the spanwise average value since in all the tested flow conditions the heat transfer coefficient exhibits a periodic fluctuation that could be ascribed to the formation of Goertler-type vortices developing in the reattaching flow region

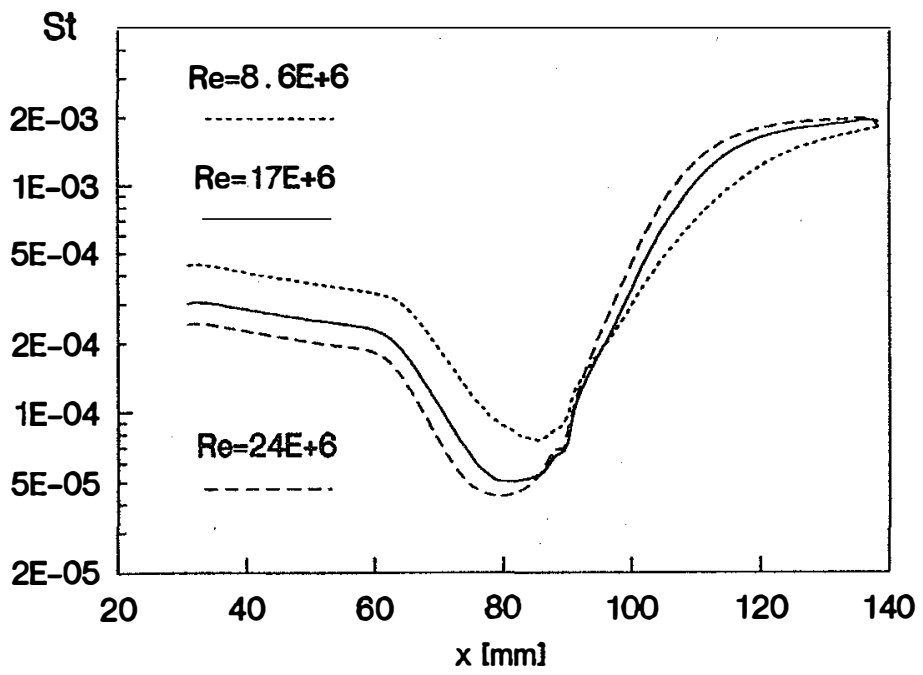

Fig.3 - Streamwise average St distributions for a flap angle of $10^{\circ}$

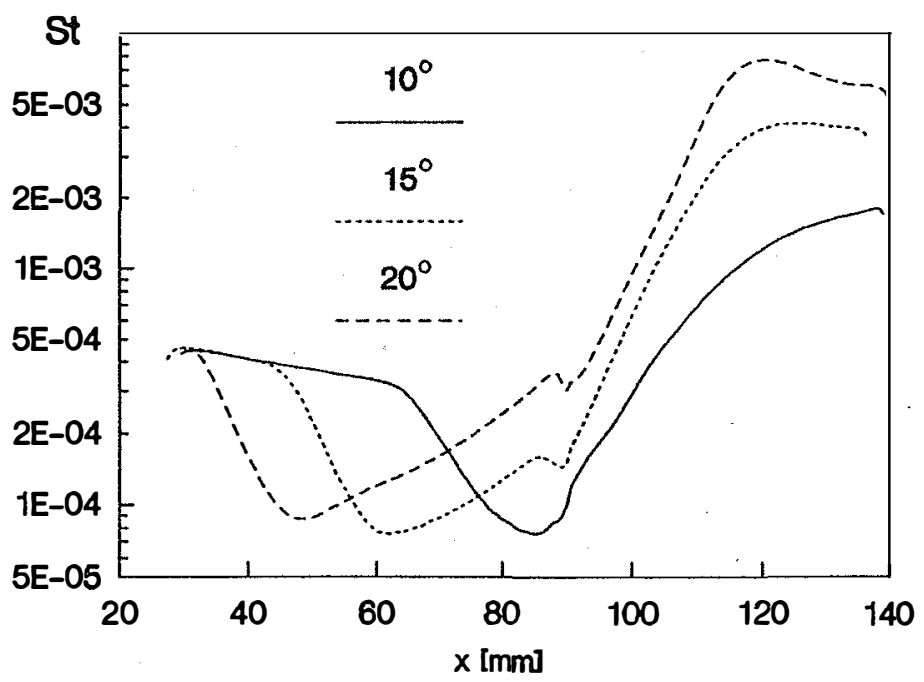

Fig. 4 - Variations of average St for various flap angles and $R e_{m}=8.6 \times 10^{6}$

To the aim of showing this effect, the spanwise St fluctuations over the ramp of the previous mentioned model for the three tested Reynolds numbers are reported in Fig. 5. Such distributions are taken along the spanwise $y$ direction where the aerodynamic heating attains its maximum value (i.e. nearly along the reattachment line). Relatively high Reynolds number as well as flap angle values (this last not shown) seem to have the effect of reducing the heat 
http://dx.doi.org/10.21611/qirt.1994.023

transfer oscillations wavelength. As far as the amount of the amplitude of such fluctuations is concerned, it seems that their absolute value remains practically constant.
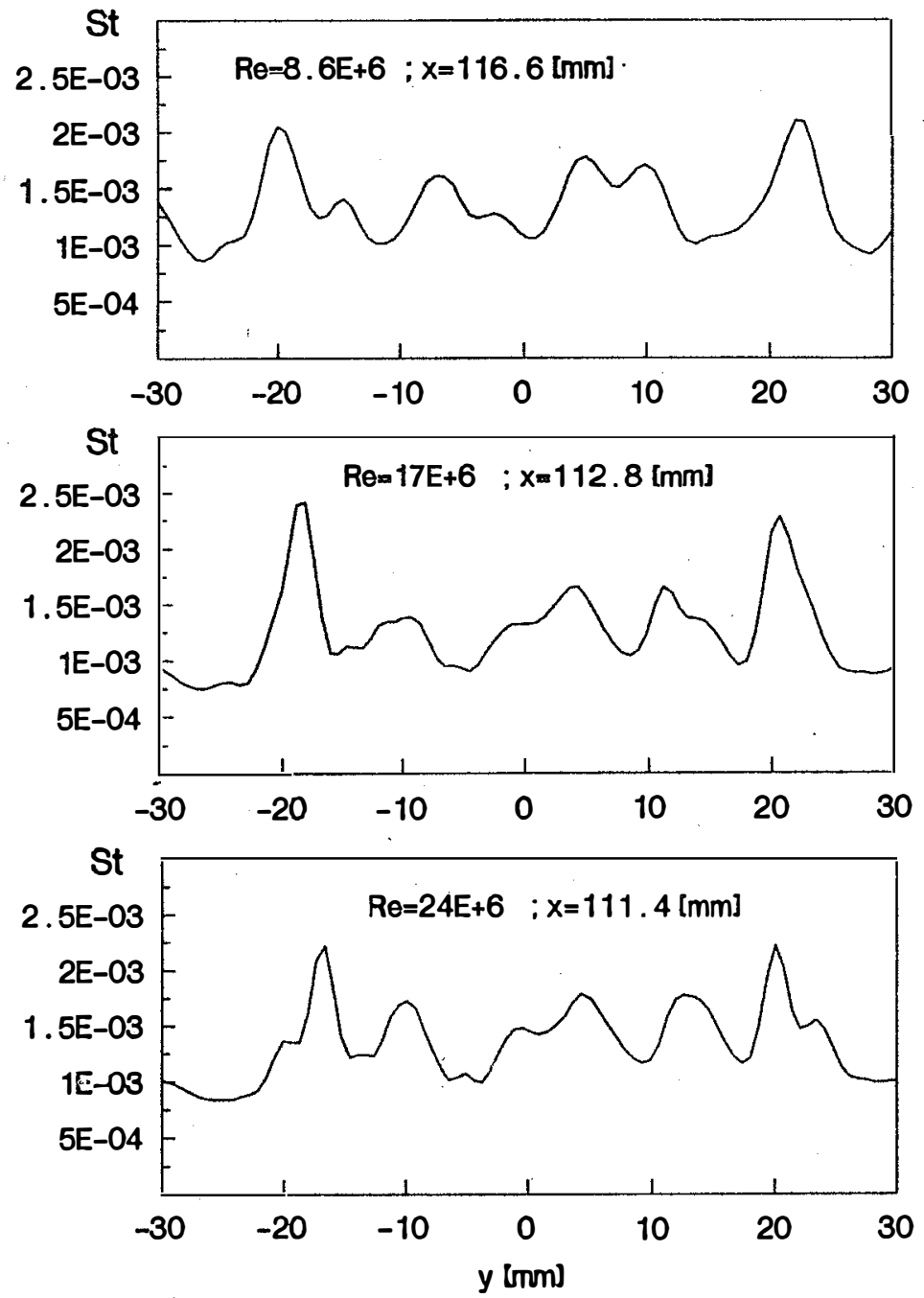

Fig.5 - Spanwise St distributions for a flap angle of $10^{\circ}$

\section{CONCLUSIONS}

An experimental investigation has been carried out to analyse the presence of Goertler-type vortices in hypersonic flow (due to 2D boundary layer/shock interactions) and their effects on the wall heat transfer: Measurements, made by means of a computerized IR imaging system, have been performed in a blowdown wind tunnel at Mach number equal to 7 and for different Reynolds numbers. The presence of Goertler vortices has been detected through the spanwise periodic variation of the wall heat transfer coefficient. 
http://dx.doi.org/10.21611/qirt.1994.023

As a main result, it has been found that the separation line moves upstream with increasing the rainp angle; the St average level on the ramp increases correspondingly, while the spanwise fluctuations wavelength decreases. Moreover, the wavelength of the spanwise fluctuations decreases with increasing $R e_{m}$

\section{REFERENCES}

[1] DEE LUCA, (L.) 1991, Computerized IR Thermography for Convective Heat Transfer Measurements, 5Th Int. Conf. on Comput. Methods and Experim. Measurements, CMEM 91, 347-358 Montreal.

[2] WENDT, (J.F.) 1989, Infrared Thermography. and Joint Europe/US Short Course on Hypers onics, Colorado Springs.

[3] CARLOMAGNO, (G.M.); DE LUCA, (L.) 1989, Infrared Thermography in Heat Transfer. Chapter 32, Handbook of Flow Visualization, (Ed. Yang, W.J.), 531-553, Hemisphere.

[4] THOMANN, (H.); FRISK, (R.), 1968, Measurement of Heat Transfer with an Infrared Camer.a. Int. J. Heat Mass Transfer, vol. 11, 819-826.

[5] BYNUM, (D. S.); HUBE, (F.K.); Key, (C.M.); DIEK, (P.M.) 1976: Measurement and Mapping of Aerodynamic Heating in VKF Tunnel $B$ with an Infrared Camera. AEDC Rpt. TR-76-54, 1-33.

[6] SIMEONIDES, (G.); VAN LIERDE, (P.); VAN DER STICHELE, (S.); CAPRIOTTI (D.), WENDT (J.F.) 1989, Infrared Thermography in Blowdown and Intermittent Hypersonic Facilities. AIAA paper 89-0042.

[7] CARLOMAGNO, (G.M.); DE LUCA, (L.); ALZIARY DE ROQUEFORT, (T.) 1989, Heat Transfer Measurements with an Infrared Camera in Hypersonic Flow. In Computers and Experiments in Fluid Flow, (Eds. Carlomagno, G.M. and Brebbia, C.A.), Comp. Mech.Springer Verlag, 467-476.

[8] CARLOMAGNO, (G. M.); DE LUCA, (L.); and ALZIARY DE ROQUEFORT, (T.) , 1991, Mapping and Measurement of Aerodynamic Heating by means of IR Thermography, in MultiPhase Flow and Heat Transfer (Eds. Xue-Jun Chen et al.), Vol. 2, pp.1316-1325, Hemisphere.

[9] BALAGEAS, (D.L.);BOSCHER, (D.M.); DEOM, (A.A.) ET FOURNIER (J.), 1991, Application de la thermographie infrarouge passive et stimulée à la measure des flux termiques en soufflerie. La Recherche Aerospatiale, 1991-4, 52-72.

[10] DE LUCA, (L); CARDONE, (G.); CARLOMAGNO, (G.M.); AYMER DE LA CHEVALERIE, (D.) and ALZIARY DE ROQUEFORT, (T.), 1992, Flow Visualization and Heat Transfer Measurement in Hypersonic Wind Tunnel. Experimental Heat Transfer, 5, 65-78.

[11] COOK, (W. J.) and FELDERMAN, (E. J.) 1966, Reduction of data from thin film heat transfer gages: A concise numerical technique, AIAA J., vol. 4, pp. 561-562.

[12] BECK, (J. V.), BLACKWELL (B.) and ST. CLAIR,( C. R.) JR 1985, Inverse heat conduction, J. Wiley. 